\title{
ANALISIS PENGARUH BUDAYA ORGANISASI, KOMPENSASI, DAN KEPUASAN KERJA TERHADAP TINGKAT TURNOVER KARYAWAN PT. YUASA BATTERY INDONESIA - TANGERANG
}

\author{
Oleh: Harjoyo
}

\begin{abstract}
PATH ANALYSIS OF ORGANIZATIONAL CULTURE, COMPENSATION AND JOB SATISFACTION ON EMPLOYEES TURNOVER OF YUASA BATTERY INDONESIA, CO,LTD.-TANGERANG. The study attempted to examine a phenomena and to gain empirical evident, as well as to get a brief data on the influence of organizational culture, compensation and job satisfaction on employee turnover. The study applied descriptive and inductive of multivariat regresion method it's include 94 respondents as the samples. The samples were selected through proporsionate stratified sampling. The statistical tool were used is SPSS 17 software as the means to examine the data. The findings could be concluded as follows: (1) There was positive effect from all independent variables toward employee turnover within value influence $80,9 \%$. (2) The results of this research indicated that job satisfaction was the greatest affecting to the employee turnover was as much as 59.1\%. (3) Meanwhile there are positive influence of organizational culture was equal to $26.7 \%$. (4) Then there are positive affecting of compensation was equal to $12.6 \%$. Based on the analysis of the conclusions and implications of this research, there are several suggestions as follows:(1) Based on the calculation results of the questionnaire, organizational culture variables $\left(X_{1}\right)$ which consists of 4 dimensions and 12 indicators, dimensions of employee engagement have a presentation of the most low at 48.94\%. It should be a concern for the company improve employee engagement as a problem-solving discussion, provides an opportunity to move forward, and so on. (2) The compensation variable $\left(X_{2}\right)$ consisting of 4 dimensions and 12 indicators, dimensions of the facility have a presentation that is equal to $51.33 \%$ lower. It should be a concern for the company improve employee facilities required such as parking areas, parks, sports facilities, so that employees feel comfortable in the company area. (3) The Job satisfaction variables $\left(X_{3}\right)$ which consists of 4 dimensions and 16 indicators, job security dimension has the lowest presentation that is equal to $52.38 \%$. It is recommended that companies pay more attention to health and safety, and social security so employees do not feel anxious in doing the job.(4) The Turnover variable (Y) consisting of 4 dimensions and 13 indicators, dimensions of the work environment has a presentation of the work value that is equal to $53.19 \%$. This is not apart from polluting production processes and pollution and generate waste hazardous and toxic material. Although the company has done with the implementation of an Environmental Management System ISO 14001 but is still expected to increase in the control of potential environmental pollution and threats, so that not only the employees in the company that would avoid the risk of pollution and contamination of the surrounding community but also will feel calm and do not disturb the existenceof the $c$ ompany.
\end{abstract}

Kata Kunci: Budaya Organisasi, Kompensasi, Kepuasan Kerja, Tingkat Trun Over Karyawan 


\section{PENDAHULUAN}

\section{Latar Belakang}

Terjadinya turnover merupakan suatu hal yang tidak dikehendaki oleh perusahaan. Turnover karyawan merupakan masalah klasik yang sudah dihadapi para pengusaha sejak era revolusi industri. Kondisi lingkungan kerja yang buruk, upah yang terlalu rendah, jam kerja yang melewati batas serta tiadanya jaminan sosial merupakan penyebab timbulnya turnover pada waktu itu , McKinnon dalam Hartati (2013: 21). Dewasa ini masalah turnover sangat diperhatikan oleh pakar ekonomi dan sosial, karena ditinjau dari berbagai sisi perusahaan akan mengalami kerugian, Cawsey and Wedley dalam Handoyo (1987: 81 ). Terlebih jika turnover tersebut terjadi dalam manajemen lini menengah, kerugian yang ditanggung oleh perusahaan akan semakin membengkak, Hartati (1992: 45).

Tingginya tingkat turnover tenaga kerja dapat diprediksi dari seberapa besar keinginan berpindah yang dimiliki anggota (staff) suatu organisasi atau perusahaan. Penelitian- penelitian dan literatur yang ada menunjukkan bahwa keinginan berpindah seseorang terkait erat dengan kepuasan gaji, kepuasan kerja, dan komitmen organisasi.

Keinginan untuk mengakhiri tugas atau meninggalkan organisasi (Mobley, 1997: 67; Judge, 1993: 81) berhubungan negatif dengan kepuasan kerja. Kepuasan kerja yang dirasakan dapat mempengaruhi pemikiran seseorang untuk keluar. Evaluasi terhadap berbagai alternatif pekerjaaan, pada akhirnya akan mewujudkan terjadinya turnover karena individu yang memilih keluar dari organisasi akan mengharapkan hasil yang lebih memuaskan di tempat lain.

Seperti halnya organisasi atau perusahaan yang lain, PT. Yuasa Battery Indonesia, sebuah perusahaan yang bergerak di industri baterai/ aki yang berlokasi di Tangerang-Banten tidak luput dari permasalahan turnover. Dari data empiris seperti pada tabel 1.1. terlihat tingkat turnover karyawan PT. Yuasa Battery Indonesia menunjukkan bahwa setiap tahunnya terjadi turnover rata-rata sebesar $1,7 \%$ 
Tabel 1.1. Tingkat Turnover Karyawan PT. Yuasa Battery Indonesia

\begin{tabular}{|c|c|c|c|}
\hline Tahun & Jumlah Karyawan & Jumlah Turnover & $\%$ \\
\hline 2007 & 1243 & 20 & 1,61 \\
\hline 2008 & 1299 & 22 & 1,69 \\
\hline 2009 & 1411 & 24 & 1,71 \\
\hline 2010 & 1462 & 23 & 1,57 \\
\hline 2011 & 1496 & 25 & 1,67 \\
\hline 2012 & 1553 & 40 & 2,58 \\
\hline
\end{tabular}

Sumber : Departemen HRD \& GA, PT. Yuasa Battery Indonesia, Tangerang, 2013

\section{Identifikasi Masalah}

Untuk mengetahui sejauh mana pengaruh budaya organisasi, kompensasi , dan kepuasan kerja kepuasan kerja terhadap tingkat turnover karyawan PT. Yuasa Battery Indonesia-Tangerang, maka penulis mengidentifikasikan masalah-masalah yang akan dibahas sebagai berikut :

1. Latar belakang budaya yang berbeda dari karyawan baik dari asal suku, sosial, ekonomi, agama, dan intelektual.

2. Untuk pencapaian tujuan organisasi, manajemen menciptakan budaya organisasi.

3. Penolakan terhadap budaya organisasi oleh sebagian karyawan.

4. Berbagai bentuk kompensasi seperti upah, tunjangan upah, pengganti cuti, pembayaran upah saat tidak bisa bekerja karena sakit, tunjangan hari tua, pesangon dan sejenisnya yang diterima karyawan.

5. Interaksi karyawan dalam menyikapi kompensasi, sebagian karyawan yang menerima akan meningkatkan produktivitas kerjanya, sedangkan sebagian karyawan yang tidak sepenuh hati menerima, akan bekerja kontraproduktif seperti malas, absen, dan mengabaikan kualitas.

6. Karyawan yang merasakan kepuasan kerja akan bertingkah laku pro aktif, kooperatif, dan bertanggung jawab, $\mathrm{s}$ ebaliknya karyawan yang tidak mendapatkan kepuasan kerja berlaku masa bodoh dan malas.

7. Karyawan yang mendapatkan kepuasan kerja akan bertahan, bahkan sampai usia pensiun, sedangkan karyawan yang tidak mendapatkan kepuasan kerja akan meninggalkan perusahaan atau melakukan penarikan diri (turnover).

8. Turnover dikarenakan karyawan tidak merasakan pemenuhan dengan apa yang diharapkan di dalam perusahaan.

9. Turnover disebabkan tidak bisa mengikuti dan adaptasi dengan 
lingkungan perusahaan, sehingga perusahaan melakukan PHK.

10. Turnover disebabkan karyawan sudah memasuki usia pensiun.

11. Turnover disebabkan karyawan meninggal dunia.

\section{Pembatasan Masalah}

Berdasarkan identifikasi masalah di atas dan keterbatasan yang dimiliki oleh penulis seperti waktu, tenaga, biaya dan pengkajian teori, penelitian ini dibatasi pada masalah yang berkaitan dengan :

"Analisis Pengaruh Budaya Organisasi, Kompensasi , dan Kepuasan Kerja terhadap Tingkat Turnover Karyawan PT. Yuasa Battery Indonesia-Tangerang ", yaitu:

1. Budaya organisasi yang ada di PT. Yuasa Battery Indonesia seperti misi perusahaan, konsistensi, adaptabilitas terhadap perubahan dan pelibatan karyawan.

2. Jenis kompensasi yang diterima karyawan PT. Yuasa Battery Indonesia seperti upah, insentif, macammacam tunjangan dan fasilitas.

3. Tingkat kepuasan kerja yang dirasakan karyawan PT. Yuasa Battery Indonesia seperti kondisi kerja, atasan atau supervisi, teman kerja dan keamanan kerja.

4. Tingkat turnover karyawan PT. Yuasa Battery Indonesia seperti ketidakpuasan terhadap manajemen, perkembangan karir, lingkungan kerja dan hubungan interpersonal.

\section{Perumusan Masalah}

Berdasarkan uraian di atas untuk mencegah terjadinya ketimpangan dan kerancuan dalam pembahasan, maka diberikan suatu perumusan masalah. Adapun perumusan masalah yang dibahas dalam tesis ini adalah sebagai berikut:

1. Bagaimana budaya organisasi, kompensasi, kepuasan kerja karyawan PT. Yuasa Battery Indonesia?

2. Seberapa besar pengaruh budaya organisaisi terhadap tingkat turnover karyawan PT. Yuasa Battery Indonesia?

3. Seberapa besar pengaruh kompensasi terhadap tingkat turnover karyawan PT. Yuasa Battery Indonesia?

4. Seberapa besar pengaruh kepuasan kerja terhadap tingkat turnover karyawan PT. Yuasa Battery Indonesia?

5. Seberapa besar pengaruh budaya organisasi, kompensasi dan kepuasan kerja bila diuji secara simultan dan faktor manakah yang paling berpengaruh terhadap tingkat turnover karyawan? 


\section{Tujuan Penelitian}

Tujuan penelitian ini adalah untuk menjawab masing-masing perumusan masalah di atas adalah sebagai berikut:

1. Menganalisis budaya organisasi, kompensasi dan kepuasan kerja karyawan PT. Yuasa Battery Indonesia saat ini.

2. Menganalisis pengaruh budaya organis asi terhadap tingkat turnover karyawan PT. Yuasa Battery Indonesia.

3. Menganalisis pengaruh kompensasi terhadap tingkat turnover karyawan PT. Yuasa Battery Indonesia.

4. Menganalisis pengaruh kepuasan kerja terhadap tingkat turnover karyawan

PT. Yuasa Battery Indonesia.

5. Menganalisis secara simultan pengaruh budaya organisasi, kompensasi dan kepuasan kerja terhadap tingkat turnover karyawan dan faktor mana yang paling berpengaruh.

\section{Deskripsi Teoritik}

\section{Budaya Organisasi}

\section{1) Budaya}

Terdapat banyak definisi

mengenai budaya atau kultur sebagaimana diadaptasi dari bahasa Inggris culture, colore dalam bahasa Latin. Secara harfiah budaya diartikan sebagai pikiran, akal budi, atau sejumlah pola sikap, keyakinan, dan perasaan tertentu yang

mendasari, mengarahkan, dan memberi arti pada tingkah laku seseorang dalam suatu masyarakat (Kamus Besar Bahasa Indonesia).

Sweeney \& McFarlin (2002: 334) mengemukakan bahwa budaya secara ideal mengkomunikasikan secara jelas pesan-pesan tentang bagaimana kita melakukan sesuatu atau bentindak, berperilaku di sekitar sini ("how we do things around

here"). Dari pemikiran tersebut dapatlah diinterpretasikan bahwa budaya memberikan arahan mengenai bagaimana seseorang harus berperilaku, bersikap, bertindak dalam suatu komunitas, kata 'here' dalam pengertian di atas mengacu pada komunitas tertentu baik itu berbentuk

organisasi, perusahaan, atau masyarakat.

Pengertian lainnya menyatakan bahwa budaya merupakan pola asumsi- asumsi dasar yang oleh suatu kelompok tertentu telah ditemukan, dibuka, atau dikembangkan melalui pelajaran untuk memecahkan masalah-masalah adaptasi eksternal dan integrasi internal, dan yang telah berjalan cukup lama untuk dipandang sahih, dan oleh sebab itu diajarkan kepada 
anggota-anggota baru sebagai cara yang benar untuk memandang, berpikir, dan merasa dalam kaitannya dengan masalah-masalah tersebut , Schein (1992: 90).

Robert A. Nisbet (1970: 110) mengemukakan bahwa budaya adalah segala sesuatu yang kita temukan dalam tingkah laku manusia dalam sebuah masyarakat yang bukan merupakan produk langsung dari struktur biologisnya.

Dari berbagai pengertian yang telah dikemukakan tersebut dapatlah dinyatakan bahwa budaya ini merupakan cara hidup termasuk di dalamnya cara berpikir, bertindak dan sebagainya dalam suatu komunitas tertentu (organisasi/perusahaan/masyarakat), sehingga membedakan karakteristik suatu komunitas dengan yang lainnya.

\section{2) Organisasi}

Konsep kedua yang berusaha penulis paparkan sehubungan dengan usaha untuk dapat lebih mema hami pengertian budaya organisasi adal ah kosep organisasi. Salah satu hal penting dalam memahami budaya organisasi adalah bahwa kita seyogianya memahami pendekatanpendekatan yang mempengaruhi cara berpikir atau cara pandang terhadap organisasi. Organisasi menurut
Robbin (2001:4) diartikan sebagai suatu unit (satuan) sosial yang dikoordinasikan dengan sadar, yang terdiri dari dua orang atau lebih, yang berfungsi atas dasar yang relatif terus menerus untuk mencapai suatu tujuan atau serangkaian tujuan bersama.

Terdapat dua pendekatan dalam memahami organisasi, yaitu pendekatan objektif dan pendekatan subjektif. Makna “objektif” dalam konteks ini merujuk kepada pandangan bahwa objek-objek, perilaku-perilaku, dan peristiwaperistiwa eksis di dunia nyata dan terlepas dari pengamatnya, sedangkan “subjektif” menunjukkan bahwa relalitas itu sendiri adalah konstruksi sosial, realitas sebagai suatu proses kreatif yang memungkinkan orang menciptakan apa yang ada "di luar sana" (Pace \& Faules , 2001: 11).

Menurut pendekatan objektif, organisasi merupakan sesuatu yang bersifat fisik dan kongkret, dan merupakan sebuah struktur dengan batas-batas yang pasti, sesuatu yang stabil. Istilah "organisasi" mengisyaratkan bahwa sesuatu yang nyata merangkum orang-orang, hubungan-hubungan, dan tujuantujuan. Pendekatan subjektif memandang organisasi sebagai 
kegiatan yang dilakukan orangorang, terdiri dari tindakan-tindakan, interaksi, dan transaksi yang melibatkan orang-orang.

Organisasi diciptakan dan dipupuk melalui kontak-kontak yang terus menerus berubah yang dilakukan orang-orang antara yang satu dengan lainnya dan tidak eksis

secara terpisah dari orang-orang yang perilakunya membentuk organisasi tersebut.

Jadi berdasarkan pendekatan objektif, organisasi berarti struktur; sedangkan berdasarkan pandangan subjektif, organisasi berarti proses (mengorganisasikan perilaku).

\section{3) Budaya Organisasi}

Terbentuknya budaya organisasi menurut Robbins (2002: 262), berawal dari filsafat pendiri organisasi (mereka mempunyai visi mengenai bagaimana seharusnya organisasi itu), budaya asli diturunkan dari filsafat pendirinya, yang kemudian berpengaruh terhada $\mathrm{p}$ kriteriayang digunakan dalam mem pekerjakan anggota/karyawannya. Tindakan manajemen puncak juga mempunyai dampak besar dalam pembentukan budaya organisasi (melalui apa yang mereka katakan dan lakukan) dan seringkali menentukan iklim umum dari perilaku yang dapat diterima dan yang tidak. Bagaimana anggota/karyawan harus disosialisasikan akan tergantung, baik pada tingkat sukses yang dicapai dalam mencocokan nilai-nilai anggota / karyawan baru dengan nilai-nilai organisasi dalam proses seleksi maupun pada preferensi manajemen puncak akan metodemetode sosialisasi.

\section{Kompensasi}

Pada dasarnya manusia bekerja juga ingin memperoleh uang untuk memenuhi kebutuhan hidupnya. Untuk itulah seorang karyawan mulai menghargai kerja keras dan semakin menunjukkan loyalitasnya terhadap perusahaan dan arena itulah perusahaan memberikan penghargaan terhadap prestasi kerja karyawan yaitu dengan jalan memberikan kompensasi. Salah satu cara manajemen untuk meningkatkan prestasi kerja, memotivasi dan meningkatkan kinerja para karyawan adalah melalui kompensasi, Mathis dan Jackson (2000:74).

Hani Handoko

(1993: menyatakan bahwa kompensasi penting bagi karyawan sebagai individu karena besarnya kompensasi mencerminkan ukuran karya mereka di antara para 
karyawan itu sendiri, keluarga dan masyarakat.

Kompensasi juga acapkali disebut sebagai penghargaan dan dapat didefinisikan sebagai setiap bentuk penghargaan yang diberikan kepada karyawan sebagai balas jasa atau kontribusi yang mereka berikan kepada organisasi , Mutiara S. Panggabean (2002: $85)$.

Selain itu dalam buku Malayu S.P. Hasibuan (2002: 17) terdapat beberapa pengertian kompensasi dari beberapa tokoh yaitu :

Menurut William B.Werther dan Keith

Davis (1996: 84), kompensasi adalah apa yang seorang pekerja terima sebagai balasan dari pekerjaan yang diberikannya baik upah per jam atau gaji periodik didesain dan

dikelolah oleh bagian personalia. Menurut Andrew F. Sikula (1999: 101), kompensasi adalah segala sesuatu yang dikonstitusikan atau dianggap sebagai suatu balas jasa atau ekuivalen.

Menurut T. Hani Handoko (2001 : 155) kompensasi adalah segala sesuatu yang diterima para karyawan sebagai balas jasa untuk kerja mereka. Sedangkan menurut Simamora (2004 : 442) kompensasi merupakan apa yang diterima oleh para karyawan sebagai ganti kontribusi mereka kepada organisasi.
Sedangkan menurut Dessler (2007 : 46) kompensasi merujuk kepada semua bentuk bayaran atau hadiah bagi karyawan dan berasal dari pekerjaan mereka.

\section{Kepuasan Kerja}

Menurut kamus besar bahasa Indonesia , kepuasan adalah perasaan senang, gembira, dan lega karena sudah terpenuhi hasrat hatinya. Sementara kepuasan kerja didefinisikan sebagai keadaan psikis yang menyenangkan yang dirasakan oleh pekerja di suatu lingkungan pekerjaan karena terpenuhinya semua kebutuhan sacara memadai. Dengan kata lain kepuasan kerja merupakan respon afektif seseorang terhadap suatu pekerjaan. Kepuasan kerja ini bersifat individual, tingkat kepuasan antara individu yang satu dengan yang lainnya berbeda-beda. Biasanya setiap individu akan merasa puas atas pekerjaannya apabila pekerjaan yang ia lakukan telah sesuai dengan harapan dan tujuan ia bekerja.

Menurut para ahli, keberhasilan dalam mengelola sumber daya manusia diindikasikan dengan adanya kepuasan kerja dari para karyawannya, meningkatnya kinerja, dan tercapainya tujuan perusahaan. Locke dalam Ali Turkylmas dkk. (2009: 118) mengartikan kepuasan kerja sebagai pernyataan emosi yang positif sebagai hasil dari pengakuan terhadap pekerjaan atau pengalaman dalam bekerja. Robbins (2008: 77) 
mengistilahkan kepuasan kerja sebagai sikap umum seseorang individu terhadap pekerjaannya, selanjutnya dijelaskan pula bahwa seseorang dengan kepuasan kerja yang tinggi menunjukkan sikap yang positif terhadap pekerjaan itu, sebaliknya seseorang yang kepuasan kerjanya rendah akan menunjukkan sikap yang negatif terhadap pekerjaannya.

Menurut Hasibuan (2007: 16)

Kepuasan kerja adalah sikap emosional yang menyenangkan dan mencintai pekerjaannya. Kepuasan kerja (job statisfaction) karyawan harus diciptakan sebaik-baiknya supaya moral kerja, dedikasi, kecintaan, dan kedisiplinan karyawan meningkat. Sikap ini dicerminkan oleh moral kerja, kedisiplinan, dan prestasi kerja. Kepuasan kerja dinikmati dalam pekerjaan, luar pekerjaan, dan kombinasi dalam dan luar pekerjaan. Kepuasan kerja dalam pekerjaan adalah kepuasan kerja yang dinikmati dalam pekerjaan dengan memperoleh pujian hasil kerja, penempatan, perlakuan, peralatan, dan suasana lingkungan kerja yang baik. Karyawan yang lebih suka menikmati kepuasan kerja dalam pekerjaan akan lebih mengutamakan pekerjaannya daripada balas jasa walaupun balas jasa itu penting.

\section{Turnover}

Jackofsky dan Peter(1983: 76) memberi batasan turnover sebagai perpindahan karyawan dari pekerjaannya yang sekarang. Cascio(1987:91) mendefinisikan turnover sebagai berhentinya hubungan kerja secara permanen antara perusahaan dengan karyawannya. Maier (1971: 46) menyebutkan turnover sebagai perpisahan antara perusahaan dengan pekerjanya, sedangkan Scott mendefinisikan gejala turnover sebagai perpindahan tenaga kerja dari dan ke sebuah perusahaan.

Beach (1980: 46) menggunakan kata termination, turnover dijelaskan sebagai berpisah atau berhentinya karyawan dari perusahaan yang mengupahnya dengan berbagai alasan. Mobley, seorang pakar dalam masalah pergantian karyawan memberikan batasan turnover sebagai berhentinya individu dari suatu organisasi dengan disertai pemberian imbalan keuangan oleh organisasi yang bersangkutan. Pemberhentian menurut Robbins (1996:77) dibedakan menjadi dua tipe yaitu turnover yang sukarela atau yang diprakarsai karyawan (voluntary turnover), dan tipe turnover yang terpaksa atau diprakarsai oleh organisasi, ditambah dengan kematian dan pengunduran diri atas desakan.

Mengacu pada beberapa definisi yang dikemukakan di atas, maka dapat disimpulkan bahwa turnover adalah keluar atau berpindahnya karyawan dari 
perusahaan baik secara sukarela maupun

terpaksa dan disertai pemberian imbalan.

\section{METODOLOGI PENELITIAN}

\section{Rancangan Penelitian}

\section{Tempat Penelitian}

Penulis melakukan penelitian ini di PT. Yuasa Battery Indonesia dengan alamat perusahaan yang terletak di Jl. $\mathrm{MH}$. Thamrin, Panunggangan Serpong Tangerang. PT. Yuasa Battery Indonesia adalah perusahaan produsen aki/baterai dan merupakan anak perusahaan dari group Yuasa yang bergerak di banyak bidang, mulai dari berbagai jenis produk Aki (Accumulator), Uninteruptible Power System (UPS), Rectifier Charger dan produk-produk lain yang berpusat di Jepang yaitu Yuasa Corporation Japan.

\section{Waktu Penelitian}

Penelitian ini dilakukan selama 4 bulan (bulan Maret 2013 sampai dengan
Juni 2013), yang belum dipaparkan dalam karya ilmiah.

\section{Jenis Pneleitian}

Penelitian ini menggunakan metode analisis regresi berganda berdasarkan penjelasan analisis kualitatif. Tujuannya adalah untuk menjelaskan aspek- aspek yang sesuai atau relevan dengan fenomena yang diamati dan menjelaskan karakteristik masalah yang ada.

Teknik sampling yang digunakan adalah proportionate stratified random sampling yakni teknik yang dilakukan berdasarkan kriteria populasi yang mempunyai unsur atau anggota tidak homogen dan proporsional (Umar Husein, 2008:112).

\section{Populasi dan Sample}

\section{Populasi.}

Penulis menentukan populasi yang diambil dalam penelitian ini adalah seluruh karyawan PT. Yuasa Battery Indonesia yang berjumlah 1553 orang.

Tabel 3.1

Jumlah Karyawan PT. Yuasa Battery Indonesia

\begin{tabular}{|c|l|c|}
\hline No. & \multicolumn{1}{|c|}{ Pegawai } & Jumlah \\
\hline 1 & Divisi Human Resource & 50 \\
\hline 2 & Divisi Purchasing \& Marketing & 22 \\
\hline 3 & Divisi Commercial & 1 \\
\hline 4 & Divisi Production & 1316 \\
\hline 5 & Divisi Technical Engineering & 150 \\
\hline 6 & Divisi IT \& Finance & 14 \\
\hline \multicolumn{2}{|c|}{ Total } & 1553 \\
\hline
\end{tabular}

Sumber: Data Sekunder 2013 


\section{Sampel}

Dalam rangka efisiensi dan efektifitas penelitian dan juga berdasarkan pada keterbatasan-keterbatasan penulis baik dari segi dana, daya maupun data sampel yang dikumpulkan dengan cara mengambil sampel

berdasarkan teknik proportionate stratified random sampling yakni teknik yang dilakukan berdasarkan kriteria populasi yang mempunyai unsur atau anggota tidak homogen dan proporsional (Umar Husein, 2008:112).Dalam penelitian ini, teknik penentuan jumlah sampel menggunakan rumus Slovin (Umar Husein, 2008:108) yaitu sebagai berikut:

$$
\mathrm{n}=\frac{\mathrm{N}}{1+\mathrm{N}(\mathrm{e})^{2}} \text { ! }
$$

Keterangan:

$\mathrm{n}=$ jumlah sampel $\mathrm{N}=$ jumlah populasi $\mathrm{e}^{2} \quad=$ Standar error $10 \%(0,1)$

Maka sampel yang diambil penulis dari seluruh populasi adalah 94 karyawan. Dengan rumus tersebut, maka jumlah sampel yang diperoleh menurut masingmasing strata adalah seperti pada tabel 3.3. sebagai berikut:

Tabel 3.2

\section{Porsi Sampel}

\begin{tabular}{|c|l|c|c|}
\hline No. & \multicolumn{1}{|c|}{ Pegawai } & \multicolumn{1}{c|}{ Jumlah } & Sampel \\
\hline 1 & Divisi Human Resource & $50 / 1553 \times 94$ & 3 \\
\hline 2 & $\begin{array}{l}\text { Divisi Purchasing \& } \\
\text { Marketing }\end{array}$ & $22 / 1553 \times 94$ & 1 \\
\hline 3 & Divisi Commercial & $1 / 1553 \times 94$ & 0 \\
\hline 4 & Divisi Production & $1316 / 1553 \times 94$ & 80 \\
\hline 5 & $\begin{array}{l}\text { Divisi Technical } \\
\text { Engineering }\end{array}$ & $150 / 1553 \times 94$ & 9 \\
\hline 6 & Divisi IT \& Finance & $14 / 1553 \times 94$ & 1 \\
\hline & Total & 1553 & 94 \\
\hline
\end{tabular}

Sumber: Data dikembangkanpeneliti

\section{Tekhnik Pengumpulan Data}

Tekhnik pengumpulan data yang digunakan dalam penelitian ini terdiri dari data primer dan data sekunder. 


\section{Data Primer}

Data primer merupakan data yang didapat dari sumber pertama baik dari individu atau perseorangan seperti hasil wawancara atau hasil pengisian kuesioner. Data primer ini dikumpulkan melalui survei dengan menggunakan kuesioner yang dibuat peneliti.

2. Data Sekunder

Data sekunder merupakan data primer yang telah diolah lebih lanjut dan disajikan baik oleh pihak pengumpul data primer atau oleh pihak lain.

\section{Metode Analisis Data}

Metode analisis yang digunakan dalam penelitianini adalah analisis regresi dengan model statistik deskriptif. Metode ini bertujuan untuk menggambarkan sifat sesuatu yang tengah berlangsung pada saat riset dilakukan dan memeriksa sebab-sebab dari suatu gejala tertentu , Trevers dalam Husein Umar( $2008: 81)$.

\section{Statistik Deskriptif}

Statistik deskriptif adalah statistik yang digunakan untuk menganalisis data dengan cara menjelaskan gambaran data yang telah terkumpul sebagaimana adanya atau aslinya tanpa bermaksud untuk membuat kesimpulan yang berlaku secara umum, Sugiyono (2007: 147). Biasanya dalam statistic deskrptif memberikan gambaran data berdasarkan min, median, modus, standar deviasi dan varians.

2. Uji Kualitas Data

Uji kualitas data digunakan untuk melihat apakah data layak untuk diuji dalam pen elitian.Dalam penelitian ini terdapat tiga pengujian data, uji validitas, uji reliabilitas dan uji normalitas. Hal ini dimaksudkan agar data benar baik dan layak untuk digunakan dalam penelitian ini dan memiliki hasil yang sesuai dengan empiris dan teori.

3. Uji Regresi Linear Berganda

Regresi linear berganda adalah regresi yang didalamnya terdapat satu variabel dependen (Y) dan lebih dari satu variabel independen (X).Variabel dependen adalah variabel terikat yang merupakan variabel yang dipengaruhi oleh variabel independen/bebas.Variabel dependen dalam penelitian ini adalah turnover karyawan. Sedangkan variabel independennya adalah budaya organisasi, kompensasi dan kepuasan kerja. Penelitian ini menggunakan model regresi linier berganda dengan menggunakan program SPSS yang dapat dirumuskan sebagai berikut:

$$
\mathbf{Y}=\alpha+\beta_{1} X_{1}+\beta_{2} X_{2}+\beta_{3} X_{3}+\varepsilon
$$

Keterangan : 


$$
\begin{array}{ll}
\mathrm{Y} & =\text { Turnover } \\
\alpha & =\text { Konstanta } \\
\beta_{1,} \beta_{2}, \beta_{3} & =\text { Koefisien variabel independent } \\
\mathrm{X}_{1} & =\text { Budayaorganisasi } \\
\mathrm{X}_{2} & =\text { Kompensasi } \\
\mathrm{X}_{3} & =\text { Kepuasankerja } \\
\varepsilon & =\text { Error }
\end{array}
$$

HASIL PENELITIAN DAN PEMBAHASAN

\section{Uji Koefisien Determinasi Variabel Budaya Organisasi}

Tabel 4.1

Uji Koefisien Determinasi Variabel Budaya Organisasi

\begin{tabular}{|c|c|c|c|c|c|}
\hline \multirow[b]{2}{*}{ Model } & \multicolumn{2}{|c|}{ Unstandardized Coefficients } & \multirow{2}{*}{$\begin{array}{c}\begin{array}{c}\text { Standardized } \\
\text { Coefficients }\end{array} \\
\text { Beta }\end{array}$} & \multirow[b]{2}{*}{$\mathrm{T}$} & \multirow[b]{2}{*}{ Sig. } \\
\hline & B & Std. Error & & & \\
\hline (Constant) & 20.892 & 3.033 & & 6.888 & .000 \\
\hline Budaya_Organisasi & .654 & .062 & .739 & 10.513 & .000 \\
\hline
\end{tabular}

\begin{tabular}{|l|r|r|r|r|}
\hline Model & \multicolumn{1}{|c|}{$\mathrm{R}$} & R Square & Adjusted R Square & \$td. Error of the Estimate \\
\hline 1 & $.739^{\mathrm{a}}$ & .546 & .541 & 3.05207 \\
\hline
\end{tabular}

Sumber : Data diolah SPSS 17

\section{Uji Regresi Sederhana Variabel Budaya Organisasi}

Tabel 4.2

Uji Regresi Sederhana Variabel Budaya Organisasi Coefficients $^{\text {a }}$

a. Dependent Variable: Turnover

Sumber : Data diolah SPSS 17

Berdasarkan output data tabel - tabel di atas diperoleh hasil bahwa budaya organisasi berpengaruh positif dan signifikan terhadap tingkat turnover karyawan sebesar 54,6\%.

\section{Uji Koefisien Determinasi Variabel Kompensasi}

Tabel 4.3

Uji Koefisien Determinasi Variabel Kompensasi Model Summary ${ }^{b}$

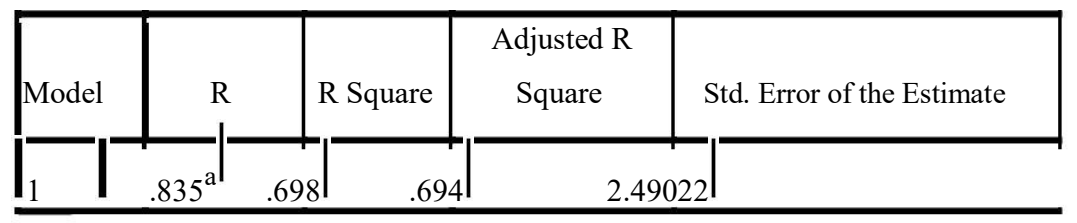

a. Predictors: (Constant), Kompensasi

b. Dependent Variable: Turnover 


\section{Uji Regresi Sederhana Variabel Kompensasi}

Tabel 4.4

Uji Regresi Sederhana Variabel Kompensasi

\begin{tabular}{|c|c|c|c|c|c|c|}
\hline \multicolumn{7}{|c|}{ Coefficients $^{\mathrm{a}}$} \\
\hline \multirow{2}{*}{\multicolumn{2}{|c|}{ Model }} & \multicolumn{2}{|c|}{ Unstandardized Coefficients } & \multirow{2}{*}{$\begin{array}{c}\text { Standardized } \\
\text { Coefficients } \\
\text { Beta }\end{array}$} & \multirow[b]{2}{*}{$\mathrm{T}$} & \multirow[b]{2}{*}{ Sig. } \\
\hline & & B & Std. Error & & & \\
\hline 1 & (Constant) & 12.180 & 2.787 & & 4.370 & .000 \\
\hline & Kompensasi & .836 & .057 & .835 & 14.567 & .000 \\
\hline
\end{tabular}

a. Dependent Variable: Turnover

Sumber : Data diolah SPSS 17

Berdasarkan output data tabel - tabel di atas diperoleh hasil bahwa kompensasi berpengaruh positif dan signifikan terhadap tingkat turnover karyawan sebesar 69,8\%.

\section{Uji Koefisien Determinasi Variabel Kepuasan Kerja}

Tabel 4.5

Uji Koefisien Determinasi Variabel Kepuasan Kerja

\begin{tabular}{|c|c|c|c|c|c|}
\hline \multicolumn{6}{|c|}{ Model Summary } \\
\hline Model & $\mathrm{R}$ & R Square $A$ & Adjusted R Square & $\begin{array}{l}\text { Std. Error of the } \\
\text { Estimate }\end{array}$ & Durbin-Watson \\
\hline 1 & $.856^{\mathrm{a}}$ & .733 & .730 & 2.33851 & 1.843 \\
\hline
\end{tabular}

a. Predictors: (Constant), Kepuasan_Kerja

b.Dependent Variable: Turnover

Sumber : Data diolah SPSS 17

\section{Uji Regresi Sederhana Variabel Kepuasan Kerja}

Tabel 4.6

Uji Regresi Sederhana Variabel Kepuasan Kerja

Coefficients $^{\mathrm{a}}$

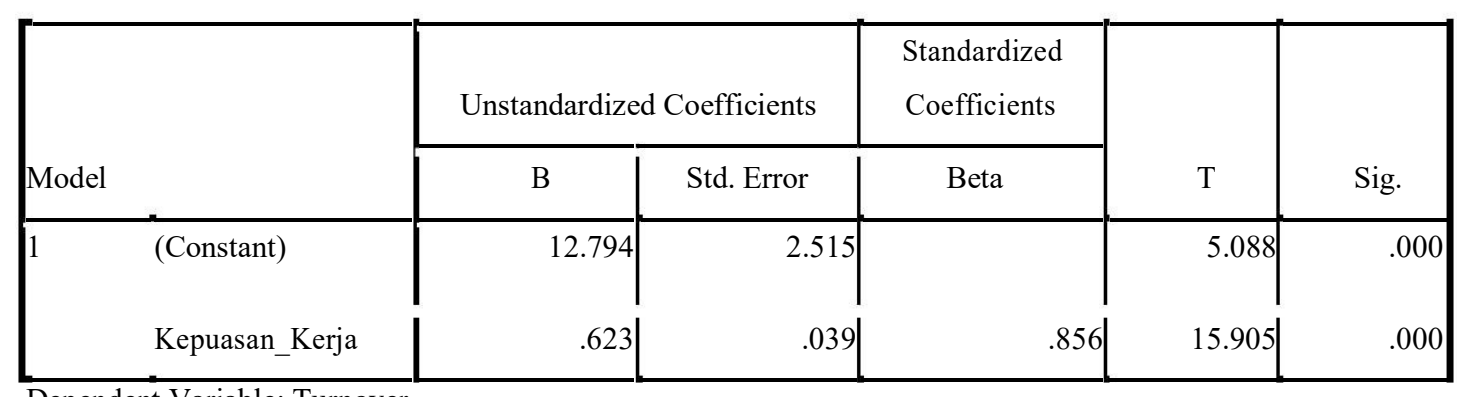

Dependent Variable: Turnover

Sumber : Data diolah SPSS 17 
Berdasarkan output data tabel - tabel di atas diperoleh hasil bahwa kepuasan kerja berpengaruh positif dan signifikan terhadap tingkat turnover karyawan sebesar 73,3\%.

\section{Uji Simultan}

\section{Uji Regresi Berganda}

Tabel 4.7

Uji Regresi Berganda

Coefficients $^{\mathrm{a}}$

\begin{tabular}{|c|c|c|c|c|c|c|}
\hline \multirow{2}{*}{\multicolumn{2}{|c|}{ Model }} & \multicolumn{2}{|c|}{ Unstandardized Coefficients } & \multirow{2}{*}{$\begin{array}{c}\begin{array}{c}\text { Standardized } \\
\text { Coefficients }\end{array} \\
\text { Beta }\end{array}$} & \multirow[b]{2}{*}{$\mathrm{t}$} & \multirow[b]{2}{*}{ Sig. } \\
\hline & & B & Std. Error & & & \\
\hline \multirow[t]{4}{*}{1} & (Constant) & 7.545 & 2.329 & & 3.239 & .002 \\
\hline & Budaya_Organisasi & .237 & .087 & .267 & 2.728 & .008 \\
\hline & Kompensasi & .126 & .131 & .126 & .963 & .338 \\
\hline & Kepuasan Kerja & .430 & .060 & .591 & 7.224 & .000 \\
\hline
\end{tabular}

Dependent Variable: Turnover

Sumber : Data diolah SPSS 17

\section{Uji Koefisien Determinasi Simultan}

Tabel 4.8

Uji Koefisien Determinasi Simultan

Model Summary ${ }^{b}$

\begin{tabular}{|l|r|r|r|r|r|}
\hline Model & \multicolumn{1}{|c|}{$\mathrm{R}$} & \multicolumn{1}{c|}{ R Square } & Adjusted R Square & $\begin{array}{c}\text { Std. Error of the } \\
\text { Estimate }\end{array}$ & Durbin-Watson \\
\hline 1 & $.899^{\mathrm{a}}$ & .809 & .803 & 2.00100 & 2.227 \\
\hline
\end{tabular}

a. Predictors: (Constant), Kepuasan_Kerja, Budaya_Organisasi, Kompensasi

b. Dependent Variable: Turnover

Sumber : Data diolah SPSS 17

\section{Uji Simultan (F)}

\section{Tabel 4.8}

Uji Simultan (F) ANOVA $^{b}$

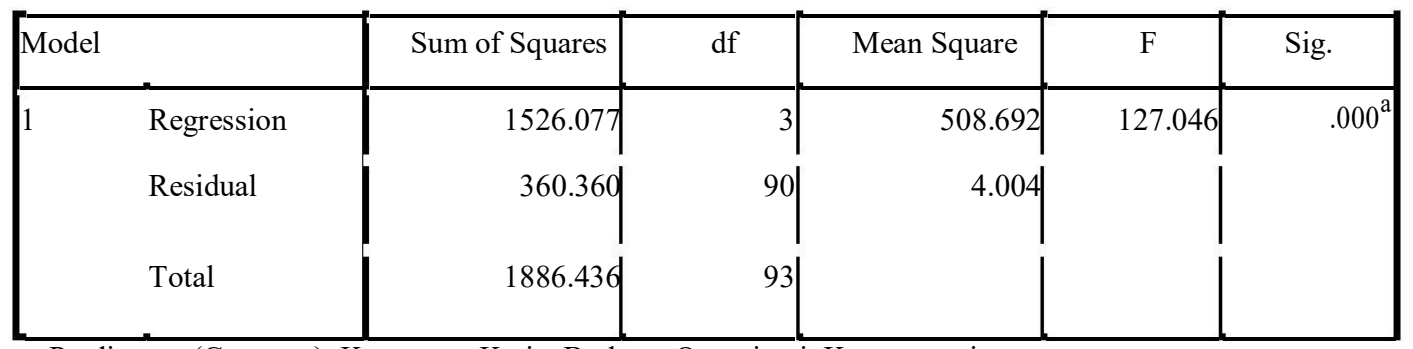

a. Predictors: (Constant), Kepuasan Kerja, Budaya Organisasi, Kompensasi 
ANOVA $^{\text {b }}$

\begin{tabular}{|c|c|c|c|c|c|c|}
\hline \multicolumn{2}{|c|}{ Model } & \multirow{2}{*}{\begin{tabular}{r|} 
Sum of Squares \\
1526.077
\end{tabular}} & \multirow[t]{2}{*}{$\mathrm{df}$} & \multirow{2}{*}{\begin{tabular}{r|} 
Mean Square \\
508.692
\end{tabular}} & \multirow{2}{*}{\begin{tabular}{|c|}
$F$ \\
127.046
\end{tabular}} & \multirow{2}{*}{$\begin{array}{l}\text { Sig. } \\
.000^{\mathrm{a}}\end{array}$} \\
\hline 1 & Regression & & & & & \\
\hline & Residual & 360.360 & 90 & 4.004 & & \\
\hline & Total & 1886.436 & 93 & & & \\
\hline
\end{tabular}

a. Predictors: (Constant), Kepuasan_Kerja, Budaya_Organisasi, Kompensasi

b.Dependent Variable: Turnover

Sumber : Data diolah SPSS 17

Berdasarkan tabel-tabel di atas mengindikasikan bahwa budaya organisasi, kompensasi serta kepuasan kerja secara bersama-sama mempunyai kontribusi sebesar 80,9\% terhadap turnover dan selebihnya sebesar 19,1\% dipengaruhi oleh variabel lain di luar penelitian ini.

\section{KESIMPULAN DAN SARAN}

\section{Kesimpulan}

Berdasarkan hasil analisa dan pembahasan penelitian dapat diambil kesimpulan sebagai berikut:

1. Berdasarkan hasil uji deskriptif budaya organisasi memiliki nilai sebesar $54.96 \%$ dengan dimensi yang paling dominan adalah adaptabilitas.

Sedangkan kompensasi memiliki nilai sebesar 57.45\% dengan dimensi yang paling dominan adalah insentif. Dan kepuasan kerja memiliki nilai 56.78\% dengan dimensi yang paling dominan adalah faktor atasan artinya secara umum budaya organisasi perusahaan, kompensasi yang diterima dan tingkat kepuasan kerja karyawan PT. Yuasa Battery Indonesia cukup baik.

2. Budaya organisasi berpengaruh terhadap tingkat turnover karyawan PT. Yuasa Battery Indonesia sebesar
$26.7 \%$, selebihnya dijelaskan oleh variabel lainnya dan faktor lain.

3. Kompensai berpengaruh terhadap tingkat turnover karyawan PT. Yuasa Battery Indonesia sebesar 12.6\%, selebihnya dijelaskan oleh varabel lainnya dan faktor lain.

4. Kepuasan kerja berpengaruh terhadap tingkat turnover karyawan PT. Yuasa Battery Indonesia sebesar 59.1\%, selebihnya dijelaskan oleh variabel lainnya dan faktor lain.

5. Budaya organisasi, kompensasi dan kepuasan kerja secara simultan berpengaruh terhadap tingkat turnover karyawan PT. Yuasa Battery Indonesia sebesar $80.9 \%$, selebihnya dijelaskan oleh variabel lain dalam penelitian ini dan dan faktor yang paling berpengaruh terhadap turnover adalah kepuasan kerja. 


\section{Saran}

Berdasarkan hasil analisis dari kesimpulan dan implikasi penelitian ini maka ada beberapa saran sebagai berikut:

1. Berdasarkanperhitunganhasil kuesioner ,variabel budaya organisasi $\left(\mathrm{X}_{1}\right)$ yang terdiri dari 4 dimensi dan 12 indikator, dimensi pelibatan karyawan memiliki presentasi paling rendah yaitu sebesar 48,94\%. Hal tersebut harus menjadi perhatian perusahaan untuk meningkatkan keterlibatan karyawan seperti diskusi pemecahan masalah, memberikan kesempatan untuk maju, dan sebagainya.

2. Pada variabel kompensasi $\left(\mathrm{X}_{2}\right)$ yang terdiri dari 4 dimensi dan 12 indikator, dimensi fasilitas memiliki presentasi paling rendah yaitu sebesar $51,33 \%$. Hal tersebut harus menjadi perhatian perusahaan untuk meningkatkan pengadaan fasilitas yang dibutuhkan karyawan seperti area parkir, taman, sarana olahraga,sehingga karyawan merasa nyaman berada di area perusahaan.

3. Variabel kepuasan kerja $\left(\mathrm{X}_{3}\right)$ yang terdiri dari 4 dimensi dan 16 indikator, dimensi keamanan kerja memiliki presentasi paling rendah yaitu sebesar $52,38 \%$. Disarankan agar perusahaan lebih memperhatikan faktor $\mathrm{K} 3$, APD dan jaminan sosial tenaga kerja sehingga karyawan tidak merasa waswas dalam melakukan pekerjaan.

4. Variabel turnover (Y) yang terdiri dari 4 dimensi dan 13 indikator, dimensi lingkungan kerja memiliki nilai presentasi paling kerja yaitu sebesar 53,19\%. Hal ini tidak terlepas dari proses produksi yang menimbulkan polusi dan pencemaran dan menghasilkan limbah B3. Perusahaan walaupun sudah melakukan Sistem Manajemen Lingkungan dengan penerapan ISO 14001 tetapi tetap dituntut untuk melakukan peningkatan pengendalian terhadap potensi dan ancaman pencemaran lingkungan, sehingga tidak saja karyawan di dalam perusahaan yang akan terhindar dari risiko polusi dan pencemaran tetapi masyarakat sekitar juga akan merasa tenang dan tidak mengusik keberadaan perusahaan.

\section{DAFTAR PUSTAKA}

Arikunto, Suharsimi, 1991, Prosedur Penelitian Suatu Pendekatan Praktek, Jakarta, Rineka Cipta.

Cascio, Wayne F., 2006, Managing Human

Resources: Productivity, Quality of Work Life, Profits, $5^{\text {th }}$ Edition, Mc. Graw-Hill Inc.,New York.

Ghozali, Imam, 2006, “ Aplikasi Analisis

Multivariate dengan Program SPSS ",

Edisi II, Penerbit Bahan Penerbit Universitas Diponegoro, Semarang. 
Gibson, James L., Ivancevich John M., Donnely James H., 1984, “

Organisasi dan Manajemen,

Perilaku, Struktur, Proses", terjemahan

Djoerban Wahid, Penerbit Erlan

BPFE. Yogyakarta.

Handoko, Hani, 1998 Manajemen

Personalia dan Sumber Daya Manusia. MSP, 1996. Manajemen Sumber Daya

Manusia. Bumi Aksara.

Jakarta.

Ivancevich J.M., 2001, Human Resource

Management, $8^{\text {th }}$ Edition, Mc Graw Hill,

New York.

Joko Sulistyo S.SI, 2012, 6 Hari Jago SPSS 17, cetakan ketiga, Penerbit

Cakrawala, Yogyakarta.

Kuswadi, 2004, Cara Mengukur Kepuasan

Kerja Karyawan, Penerbit PT. Elex

Media Komputindo, Jakarta.

Mobley, W.H. 1986. Pergantian Karyawan : Sebab-Akibat dan Pengendaliannya.

Rivai, Veithzal., 2004, Manajemen

Sumberdaya Manusia untuk Perusahaan.

PT. Raja Grafindo Persada, Jakarta.

S. Robbins, 2006. Perilaku Organisasi.

(Organizational Behavior). Jakarta: PT.

Prehalindo.

Simmamora, Henry. 1997. Manajemen

Sumberdaya Manusia. Bumi Aksara,

Jakarta.

Sugiyono, 2004. Metode Penelitian

Bisnis. Bandung: CV. Alfabeta. 